\title{
Chemical treatment of animal feed and water for the control of Salmonella
}

\author{
Andrew. D. Wales ${ }^{a} *$, Vivien. M. Allen ${ }^{\text {b }}$, Robert. H. Davies ${ }^{\text {a }}$ \\ ${ }^{a}$ Department of Food and Environmental Safety, Veterinary Laboratories Agency, Woodham Lane, New Haw, \\ Addlestone, Surrey KT15 3NB, UK. ${ }^{\mathrm{b}}$ Department of Clinical Veterinary Science, University of Bristol, \\ Langford, N. Somerset, BS40 5DU, UK.
}

*Author for correspondence and reprint requests: Robert H. Davies, Ph.D., B.V.Sc.

\author{
Address: Department of Food and Environmental Safety \\ Veterinary Laboratories Agency \\ Woodham Lane, New Haw \\ Addlestone, Surrey KT15 3NB \\ United Kingdom \\ Email: r.h.davies@vla.defra.gsi.gov.uk
}




\section{Abstract}

The control of Salmonella in animal feedstuffs is important, principally to protect the human food chain from contamination by Salmonella derived from infected animals. The transmission of Salmonella from animal feeds to animals, and onwards to human food products, has been convincingly documented. This is especially important for chicken breeding and laying flocks and pigs, in view of the consequences of recent or imminent control legislation in the European Union. Animal feed ingredients, particularly animal and plant-derived protein meals, are frequently contaminated with Salmonella either from source or from processing plant, and recontamination in compounding mills is an additional problem. Several complementary strategies have been used to control this feed contamination, and these include a range of chemical treatments. The principal agents used are: organic acids and their salts, formaldehyde, and bacterial membrane disruptors such as terpenes and essential oils. Experimental agents include chlorate compounds. Many products use blends of agents from the same or different chemical groups to achieve synergistic or combination effects. The present review draws upon published and company data to describe the various modes of action and efficacies of different chemical agents delivered in feed or in drinking water against Salmonella occurring in feed or in livestock environments. Reasons for the failure of protection are explored, along with problems in usage such as corrosion and reduced palatability. Given the wide array of products available with contrasting modes of action, the need for standardised tests of efficacy is also discussed.

Keywords: Animal feed, Salmonella, organic acid, formaldehyde, chlorate, terpene, essential oil 


\section{Introduction}

Human non-typhoidal salmonellosis remains a significant issue in public health. In 2007 there were over 155,000 reported cases in the European Union (EU) and associated countries (European Food Safety Authority, 2009), and several times this number are probably unreported (Mead et al., 1999; Wheeler et al., 1999; European Food Safety Authority, 2006b). Food is the major route of transmission of non-typhoidal salmonellas to humans (Mead et al., 1999; Crump et al., 2002), and animal food products (especially poultry, pig and bovine meat, eggs and dairy) are the vehicles primarily implicated (Enternet surveillance hub, 2006; European Food Safety Authority, 2009). Confirmed foodborne outbreaks of human salmonellosis in the EU show a heavy predominance of serovars Enteritidis and Typhimurium.

Ingredients for animal feedstuffs are commonly contaminated with Salmonella (Hacking et al., 1978; Kidd et al., 2002; Jones and Richardson, 2004; Dargatz et al., 2005; European Food Safety Authority, 2006a; Veterinary Laboratories Agency, 2006). Cereal and vegetable ingredients may come in contact with wildlife excreta and agricultural effluents during growth, harvesting, storage and transport (Bains and MacKenzie, 1974; Bauer and Hormansdorfer, 1996; Beuchat and Ryu, 1997). Animal by-products (fishmeal and, where permitted, feather meal and meat and bone meal) may be heavily contaminated from source (Nesse et al., 2003), and processing of this material into its final form often provides opportunities for Salmonella to survive and recontaminate the product (Gabis, 1991). Vegetable protein sources are commonly derived from processed oilseeds (e.g. soya and rape), and these meals are particularly prone to contamination by salmonellas that are endemic in the processing plants (Morita et al., 2003; European Food Safety Authority, 2006a).

Salmonella is commonly also found in compounded feeds, including those that have undergone heat treatment (Hacking et al., 1978; Cox et al., 1983; Veldman et al., 1995). Recent national data from EU countries (European Food Safety Authority, 2006a) shows that in most countries $0 \%-1.5 \%$ of compounded poultry feed samples are Salmonella-positive, although higher frequencies are seen in some countries.. Similar contamination rates are reported for pig and cattle feeds.

When most probable number estimates of Salmonella levels are carried out on finished feeds they are usually very low (Taylor and McCoy, 1969) but it is not certain whether it is individual organisms which are being counted or microcolonies attached to small feed particles. Microcolonies will manifest as single colony-forming units in quantitative culture, yet will present several times this number of viable Salmonella cells to the host upon ingestion, equivalent to an experimental broth culture dose with a higher nominal count. Salmonellas present in feed may also be protected by fatty material and cause infection with very low numbers (Jones et al., 1982). The infective dose is lower for animals under stress (such as poultry at the onset of lay), those suffering intercurrent disease, and very young animals where the infective dose can be below $1 \mathrm{cfu} / \mathrm{g}$ (Schleifer et al., 1984; Hinton, 1988). Salmonella present in low numbers in feed may multiply in warm, moist conditions such as feed bins and ad-lib feed hoppers.

Studies have shown strong links between Salmonella contamination of feedstuffs or feed mills and infections with the same serovars of groups in chickens, turkeys, pigs and cattle (Newell et al., 1959; Boyer et al., 1962; Glickman et al., 1981; Jones et al., 1991; Primm, 1998; 
Davies et al., 2001; Davis et al., 2003; Nayak et al., 2003; Österberg et al., 2006)..When a serovar or strain that is well-adapted for persistence is introduced via feed, its establishment in breeder and then production flocks can be rapid and widespread (Shapcott, 1985).

It has been amply demonstrated that Salmonella strains, including $S$. Typhimurium, from broiler feed sources can correlate with those found in birds and on derived broiler meat (Pennington et al., 1968; Semple et al., 1968; MacKenzie and Bains, 1976; Shapcott, 1985; Humphrey and Lanning, 1988; Davies et al., 2001; Corry et al., 2002; Bucher et al., 2007). Similar evidence exists for turkey feed serovars in birds and subsequently in slaughter and processing facilities (Bryan et al., 1968). Salmonella contamination from animal feed may also pass more directly into the human food chain via eggs or milk (Knox et al., 1963) or more indirectly through breeding flocks (Jones et al., 1991).

The need for controls on sources of Salmonella in farmed animals has been heightened by recent legislation in the European Union, where the European Food Safety Authority is in the process of defining and adopting verifiable and enforceable targets for the herd or flock-level prevalence of Salmonella among important farmed species. Regulation (EC) No. 1003/2005 requires that five serovars of public health importance are present in no more than $1 \%$ of breeding hen flocks of over 250 birds by the end of 2009. Regulation (EC) No. 1168/2006 stipulates annual minimum percentage reductions in the prevalence of laying flocks infected with either $S$. Enteritidis or $S$. Typhimurium for each member state. Work to establish regulations concerning Salmonella in broilers, turkeys and pigs is in progress, with a target level for contamination in pig production soon to be set that is likely to have a significant impact on preventive actions at farm level.

The principal approaches to reducing and eliminating Salmonella in animal feedstuffs centre upon monitoring and control of contamination in ingredients, process control and monitoring, often using the Hazard Analysis/Critical Control Point (HACCP) model, thermal treatments during feed manufacture, and chemical treatments applied at one or more stages of manufacture and storage. These approaches are, to varying extents, complementary, and all have their associated costs and technical weaknesses. For these reasons, manufacturers and users of animal feeds will typically employ a range of tactics, including chemical treatments, in attempts to suppress, eliminate or prevent Salmonella contamination. The principal chemical agents used are organic acids and formaldehyde, although blended products may additionally employ surfactants, bacterial membrane-disrupting compounds and other elements.

Chemical treatment of feed may exert its effect before it is consumed, and/or upon ingestion when the feed is moistened by the animal's alimentary secretions and encounters the $\mathrm{pH}$ conditions and endogenous acids in the crop, rumen, stomach and intestines, according to species (Cherrington et al., 1991). The antimicrobial effects may be rapid or slow and progressive, and a particular advantage of chemical treatments is that the antimicrobial capability may persist during storage, thereby helping to protect the feed against recontamination. However, persistence of the chemical can also be a disadvantage if it interferes with microbiological testing and the detection of any residual organisms that are still viable, a phenomenon referred to as 'masking'. Some treatments may principally be aimed at suppressing existing endemic Salmonella infections, often using agents that are mainly or entirely active in vivo, delivered via feed or drinking water. This is becoming a more active field with the recent restrictions and bans on antibiotic growth promoters in many countries. 
The present review summarises and discusses the literature on chemical treatments for Salmonella as applied to feed and water. These treatments vary in composition, application and aims, and their efficacy is subject to many factors encountered in feed, feedmills and on farms. The review aims to present and explain the essentials of usage, effects and limitations of these agents, in a field where information has tended to be fragmented and incomplete and where, in consequence, costly treatments can fail to perform as anticipated.

\section{Organic acids and derivatives}

\section{Suitability for use in animal feedstuffs}

Organic acids and their salts are relatively stable in feed and some of them occur naturally in living organisms, especially in the alimentary tract. They are selected for use in animal feeds because they are generally metabolised by recipient animals, or if stabilised they may pass through unabsorbed, and therefore leave no residues in foods of animal origin. Individual acids vary in their effect on Salmonella but, in general, medium-chain fatty acids are more effective than short-chain fatty acids (van Immerseel et al., 2002). Within the EU, such substances are classed as preservatives, which are defined in Regulation (EC) No. 1831/2003 as substances that protect feed against deterioration caused by micro-organisms or their metabolites.

Mode of action and relative efficacy. Organic acids are weak acids, meaning that acid $\mathrm{pH}$ they are only partly dissociated into charged organic anions and protons. Their acid dissociation constants $\left(\mathrm{pK}_{\mathrm{a}}\right.$ values) correspond to the $\mathrm{pH}$ values at which they are $50 \%$ dissociated in aqueous solution, and these are within the range 3 to 5 for the short- and medium-chain fatty acids that are of greatest interest in the present context. In solutions with low $\mathrm{pH}$ values, more of the acid molecules will be undissociated and, because in this state they carry no net charge, they can pass through the lipid membranes of bacterial cells (Ricke, 2003). Once in the bacterial cytoplasm, a high proportion of the acid molecules will dissociate at the near-neutral $\mathrm{pH}$ found in this environment, releasing protons and organic acid anions. There is evidence that the antibacterial effect of organic acids is due primarily to their ability to disrupt cellular $\mathrm{pH}$ gradients and intracellular regulation of $\mathrm{pH}$, so that vital metabolic processes are also disrupted (Cherrington et al., 1990; van Immerseel et al., 2006). In addition to the disruption of bacterial intracellular $\mathrm{pH}$, direct toxic effects of organic anions in areas including membrane structure, osmolarity and macromolecule synthesis have been hypothesised (Cherrington et al., 1990; Russell, 1992; Ricke, 2003; van Immerseel et al., 2006). Salmonella may become relatively tolerant to acid $\mathrm{pH}$ with exposure, reducing the susceptibility of the organism to strong (mineral) acids, which penetrate the cell less well than organic acids at comparable $\mathrm{pH}$ values. However, acid-adapted cells may still be vulnerable to the toxic effects of organic acids (Baik et al., 1996). In relation to the colonisation of livestock, acids may interfere with the expression of virulence genes, thereby reducing the ability of Salmonella to penetrate the intestine and survive inside macrophages, although prior exposure to acids can avoid these effects by habituation of the organisms (Kwon and Ricke, 1998; de Jonge et al., 2003; Greenacre et al., 2006; El-Sharoud and Niven, 2007).

The direct toxic effects of organic acid anions may be the principal reason why the overall inhibitory effects vary between acids. Determination of minimum inhibitory concentrations 
(Diebold and Eidelsburger, 2006) showed that effects of acids on $S$. Typhimurium could be ranked as follows: formic $>$ propionic $>$ lactic. However, the influence of $\mathrm{pH}$ was not considered. Another study (Martin and Maris, 2005) demonstrated that formic acid was more potent than acetic, propionic, lactic or citric acids, while earlier work (Khan and Katamay, 1969), using an agar disc-diffusion assay, showed that the most effective acids against Salmonella were the four- and five-carbon (C4 and C5) compounds butyric and valeric acids, and acids with a carbon chain length greater than six were the least inhibitory. More recent studies on growth suppression of $S$. Enteritidis in nutrient broth at $\mathrm{pH} 6$ (van Immerseel et al., 2003, 2004a, 2006) have shown that C6 to C12 fatty acids have greater potency than C1 to C4 acids at equivalent molar concentrations. According to Skrivanova et al. (2006), who tested a range of acids at concentrations up to $0.5 \%$, only caprylic acid (C8) was inhibitory to Salmonella at $\mathrm{pH}$ 6. Data reviewed by van Immerseel et al. (2006) suggest that factors such as chain-length, side-chain composition, $\mathrm{pK}_{\mathrm{a}}$ values and hydrophobicity can all affect antimicrobial activity.

Among E. coli, the pattern of resistance to differing organic acids at low $\mathrm{pH}$ has been shown to be highly strain-dependent (Buchanan and Edelson, 1999), a finding which may apply to other Enterobacteriaceae and which perhaps accounts in some measure for the inconsistent rankings of chemical agents between investigators. The susceptibility of Salmonella to acids also shows strain variation, illustrated by Berk et al. (2005) for strains of $S$. Typhimurium DT104 in relation to inorganic acids. Following exposure at $\mathrm{pH} 2.5$ for $2 \mathrm{~h}$, the percentage survival of different strains varied from $<0.01 \%$ to $>10 \%$, i.e. greater than 1000 -fold. Strains known to be highly virulent for humans tended to be more acid-resistant. The situation is further complicated by interactions with the food matrix in which the acid is incorporated. A range of enteropathogens, including Salmonella, were substantially protected against low $\mathrm{pH}$ challenge when inoculated onto the surface of foods composed of protein (precipitated egg white) or protein plus fat (beef), and a localised $\mathrm{pH}$-buffering effect was hypothesised (Waterman and Small, 1998). Hansen et al. (1995) showed that salmonellas in naturallycontaminated processed cottonseed matrix s were more resistant to formic or formic plus propionic acids than they were in the corresponding form of rapeseed, although the relative contributions of strain and food matrix to this phenomenon were not determined.

Efficacy is also influenced by the initial level of feed contamination and whether the target organism occurs naturally or is added artificially, the latter effect probably reflecting the degree of integration of the organism within the feed matrix and its physiological state. The presence or absence of other micro-organisms can be significant, as prior sterilisation of chemically-treated feed considerably enhanced the elimination of a subsequent inoculum of Salmonella (Ricke, 2005). Other factors affecting the apparent efficacy of organic acids are the conditions of $\mathrm{pH}$ and moisture under which effects are measured, i.e. more acidic environments enhance the antimicrobial effects of organic acids, while increasing moisture alters organic acid activity and concentrations, but also Salmonella growth potential. There is also the possibility of a 'masking' effect in bacteriological tests, whereby the $\mathrm{pH}$ value of the recovery medium is modified to a point where growth of any surviving Salmonella is inhibited (Carrique-Mas et al., 2007). Results can also be affected by the time between application of the treatment preparation and measurement of its effects, and whether the measured outcome involves ingestion of the treated feed.

All the above factors contribute to variations in observed outcomes between (and sometimes within) studies, but in many cases certain potentially-relevant factors have been either not 
measured or not reported. The methodology and media employed for isolating and enumerating Salmonella will also contribute to inter-study variations in observed efficacy.

For ease of application and safe handling of treated feed, organic acids may be used in the form of stabilised preparations, salts or appropriate mixtures of salts and straight acids. When added thus, it is likely that the organic ions will exert much of their effect only when the feed is ingested, i.e. in the dissolved state and associated with protons in a low $\mathrm{pH}$ environment.

The effects of organic acids on bacterial virulence and acid tolerance has led some to express concern that the use of such compounds in feed may enhance the pathogenicity to humans of surviving bacteria (de Jonge et al., 2003; Fratamico, 2003; Theron and Lues, 2007; ÁlvarezOrdóñez et al., 2008, 2009). However, at present this remains a theoretical possibility and it is not clear to what extent exposure to added acids might increase the virulence or survival of bacteria, or select for pre-existing minority populations of resistant organisms, over and above any effect associated with endogenous acids in the alimentary tract of animals. Furthermore, to pose a threat to human consumers any increased tolerance or virulence associated with acids in animal feed or water would need to persist through slaughter, food processing, storage and cooking stages, i.e. probably representing a genetic selection rather than a phenotypic adaptive response. In a study of Shigella, (Enterobacteriaceae), highly acidresistant survivors of a simulated gastric environment exhibited acid survival kinetics when re-cultured that were similar to that of the less acid-resistant parental strain (Gorden and Small, 1993). Another study showed that induced acid tolerance may actually reduce virulence characteristics of Salmonella strains (Karatzas et al., 2008). Thus, at present there is little or no evidence that acid exposure in livestock feed or water might lead to a persistent enhancement of bacterial virulence.

Acid treatment of feed. The treatment of feedstuffs may be done before or after compounding into finished feed. Preparations may comprise straight acids applied via spray nozzles or adsorbed onto inert powder carriers, or powdered blends of acids and acid salts. As already discussed, organic acids may achieve the goal of Salmonella reductions in one or both of two modes: toxicity exvivo associated with relatively high concentrations in feed (significantly depressing $\mathrm{pH}$ ) or toxicity exerted in vivo after ingestion. The latter mode operates even when the $\mathrm{pH}$ of the treated feed remains near neutral prior to ingestion. For in vivo effects, the local environment created by the host and its microflora, in which chemical treatments may act, varies substantially between regions of the alimentary tract, and also between livestock species.

In studies of young and mature chickens the crop and gizzard were moderately acidic ( $\mathrm{pH}$ generally around or below 5), the caecum was mildly acidic ( $\mathrm{pH}$ around 5.7), and the small intestine and colon were near neutral with $\mathrm{pH}$ values between 6.4 and 7.6 (Hume et al., 1993; Thompson and Hinton, 1997; Al-Natour and Alshawabkeh, 2005). Thus, ingested free organic acids are likely to be present in the highest luminal concentrations in the foregut (crop and gizzard), where the $\mathrm{pH}$ conditions are most conducive to their lethal effects. By contrast, endogenous organic acids (short-chain and lactic) are most concentrated in the fermentative environment of the hindgut, where their lethal effects are likely to be attenuated by the prevailing $\mathrm{pH}$. Pigs lack a crop, therefore ingested acids pass directly to the usually highly acid environment of the stomach, where their microbicidal effect should be enhanced. Similar to chickens, the porcine small and large intestines have higher organic acid concentrations but $\mathrm{pH}$ values around neutral, although the caecum is mildly acidic (Högberg and Lindberg, 
2004). Ruminants differ substantially from monogastric species, having a fermenting foregut with a high volatile organic acid concentration but a mildly acidic to neutral $\mathrm{pH}$ (Briggs et al., 1957; Church, 1979; Kleen et al., 2003). Similar conditions exist in the ruminant hindgut (Lewis and Dehority, 1985).

The toxicity of particular organic anions appears to be a feature in addition to $\mathrm{pH}$ effects, and combinations of organic acids and/or their salts can be additive or synergistic. Mixtures of organic acid salts, with or without organic acids and other elements, are commonly marketed. These have widely differing $\mathrm{pH}$ values and appear to have highly variable antibacterial effects, from one product to another, in dry feed. The organic acid derivative potassium diformate has been licensed as a non-antibiotic in-feed growth promoter in pig production, and it has also shown potential as an anti-Salmonella agent (Dennis and Blanchard, 2004; Papenbrock et al., 2005).

When used in ingredients prior to compounding, acids tend to be used at relatively high concentrations to achieve significant reductions in potentially heavy contamination of ingredients. The most marked antibacterial effects before the ingestion of feed are seen when application rates are high enough to substantially depress feed $\mathrm{pH}$, probably to less than 5 . These inclusion rates (usually $2-3 \%$ ) are really only suitable for ingredients, as they cause palatability problems in finished feed and corrosion of steel feeding equipment (Pinchasov and Jensen, 1989; Adams, 1991). The eventual concentrations in the compounded feed of acids added at the ingredient stage are obviously dependent on inclusion rates in the final blend, plus any losses in processing, for example during heat treatment. Thus, the principal effect aimed for is a rapid ex vivo Salmonella kill in the affected ingredient batch.

In an examination by Hansen et al. (1995) of naturally Salmonella-contaminated high-protein oilseed residues, the application of formic acid or formic plus propionic acids was associated with an apparent $2-3 \log _{10}$ unit reduction in contamination within $24 \mathrm{~h}$, but only when the feedstuff $\mathrm{pH}$ was below 5 , i.e. at inclusion rates of $\geq 2 \%$. Little additional kill effect was seen beyond $24 \mathrm{~h}$. Propionic acid alone was less effective than formic acid at equivalent concentrations. A blend of formic and propionic acids applied at $1.5 \% \mathrm{w} / \mathrm{w}$ consistently rendered artificial contamination of $10^{2} \mathrm{cfu} / \mathrm{g}$ Salmonella in fishmeal undetectable by sensitive culture after $24 \mathrm{~h}$ or more (Carrique-Mas et al., 2007), although some masking was demonstrated. The same treatment was generally ineffective for the elimination of higher level contamination $\left(10^{3}\right.$ or $\left.10^{4} \mathrm{cfu} / \mathrm{g}\right)$. Al-Natour and Alshawabkeh (2005) reported similar findings, wherein $1.5 \%$ formic acid in dry feed reduced $\mathrm{pH}$ to around 5 and reduced inoculated $S$. Gallinarum levels by about $1.5 \log _{10}$ units more than in untreated controls over seven days.

Notably less effect ex vivo has been seen at lower inclusion levels of short-chain organic acids, or with organic acid salts or buffered mixes of acids and their salts. In artificially contaminated dry feed over seven days, de Albuquerque et al. (1998) reported that a formic/propionic acid mix at $\leq 0.6 \%$ did not measurably reduce Salmonella counts, whereas Al-Natour and Alshawabkeh (2005) found a modest reduction of $0.9 \log _{10}$ units more than controls in feed treated with $0.5 \%$ formic acid. Similarly, a formic/propionic acid mix added at $0.50-0.68 \%$ w/w to poultry feed contaminated with Salmonella (initially adsorbed onto desiccated coconut to promote dispersal within the feed) had modest effects on Salmonella isolation rates over three weeks (Hinton and Linton, 1988). A propionic acid/phosphoric acid/isopropyl alcohol blend at $0.2 \%$ did not reduce the level of artificial Salmonella contamination of chick feed over 10 days (Duncan and Adams, 1972), and Smyser and 
Snoeyenbos (1979) reported that low concentrations of organic acids or their salts $(\leq 0.3 \%$ w/w in dry meal, including acetic acid and propionate salts) did not measurably inhibit Salmonella growth in highly moisturised meat and bone meal with $\mathrm{pH}$ values of 5.3 - 6.6.

Buffered propionic acid ( $\mathrm{pH}$ 6.8) was associated with only modest Salmonella reductions of up to $1 \log _{10}$ unit after seven days in artificially $S$. Typhimurium-contaminated poultry mash, even with high inclusion levels of up to $10 \%$ (Ha et al., 1998). Park et al. (2003) reported that sodium acetate or propionate $(1 \% \mathrm{w} / \mathrm{w})$ did not significantly affect the rate of decline (one $\log _{10}$ unit over nine days) of $S$. Typhimurium contamination introduced to sterile poultry mash. However, a buffered organic acid mix applied at $0.3 \%$ (liquid) to $0.5 \%$ (powder) to artificially contaminated poultry meal was associated with a reduction in Salmonella counts by $24 \mathrm{~h}$ that was $>1 \log _{10}$ unit higher than an untreated control (Hall, 1988). This product applied to naturally contaminated meat and bone meal at between 0.25 and $2 \%$ was also associated with reductions of between 1 and $2 \log _{10}$ units in most probable number counts of Salmonella by seven days (Pumfrey and Nelson, 1991). A progressive decline was seen over time with the lower application rates, whilst most effect was seen by $24 \mathrm{~h}$ with a $2 \%$ concentration. Other organic acid-plus-salt preparations $(0.1-0.3 \%$ inclusion rates $)$ were associated with a $1-2 \log _{10}$ unit reduction after $24 \mathrm{~h}$ in counts of $S$. Typhimurium previously inoculated into poultry feed (Moustafa et al., 2002).

Thompson and Hinton (1997) attempted to model the actions of ingested organic acids in vivo in the foregut of the chicken. They replicated in vitro the $\mathrm{pH}$ (around 4.5) and levels of lactic, propionic and formic acid found in the crops of mature layer hens given feed treated with $0 \%$, $0.68 \%$ or $1.2 \%$ of a product containing $68 \%$ formic acid plus $20 \%$ propionic acid. All the acid mixes had similar bactericidal effects against inoculated $S$. Enteritidis, but there was an additional sublethal injury, manifested as a reduction in counts on selective media, seen in the presence of formic plus propionic acid. Measurements in vivo did not demonstrate any depression of crop $\mathrm{pH}$ when the product was in the feed, and showed that formic and propionic acid had largely been absorbed by the time ingesta reached the gizzard. Another study (Hume et al., 1993) reported the crop pH of young chicks to be in the range 4.6 - 5.3, and to be unaffected by propionic acid at $0.5 \%$ in the feed. By contrast, Al-Natour and Alshawabkeh (2005) reported that 0.5 to $1.5 \%$ formic acid in the diet modestly, but consistently, depressed the $\mathrm{pH}$ of the crop and the small and large intestines by up to 0.3 (intestines) or 0.4 (crop) units.

Experiments involving live animals (generally poultry) fall broadly into those where Salmonella is presented as a bolus dose, those where it is artificially inoculated into feed, and those where the feed is naturally contaminated. Feed with $0.7 \%$ acetic and $5.7 \%$ lactic acids was not protective of young chicks against the excretion of $S$. Enteritidis administered by an oral bolus of $10^{2}-10^{6} \mathrm{cfu}$ per bird (Heres et al., 2004). Several other studies have shown that organic acids and/or salts in feed generally fail to protect poultry from colonisation by Salmonella when it is administered as single or multiple high doses (generally $10^{4}-10^{5} \mathrm{cfu}$ ) by the oral route (Izat et al., 1990a; Hinton et al., 1991; McHan and Shotts, 1992; Hume et al., 1993; Waldroup et al., 1995; Allen, 1997; Al-Natour and Alshawabkeh, 2005). Notable exceptions, i.e. effective protection, have been reported when inclusion rates have exceeded $2 \%$, associated with depression of crop and caecal $\mathrm{pH}$ values (Al-Tarazi and Alshawabkeh, 2003), and when the microbial dose has been lower, at $10^{2.5} \mathrm{cfu}$ (Allen, 1997). Relative protection may be seen: reductions in caecal counts and the proportion of positive cloacal swabs were observed with $0.3 \%$ caproic acid in chick feed plus an oral dose of $10^{3} \mathrm{cfu}$ $S$. Enteritidis at six days of age (van Immerseel et al., 2004a). Buffered propionic acid at $0.4-$ 
$0.8 \% \mathrm{w} / \mathrm{w}$ in feed was associated with a reduction in Salmonella counts in carcass rinses from broilers exposed to $10^{5}-10^{6} \mathrm{cfu} / \mathrm{ml} S$. Typhimurium in drinking water (Izat et al., 1990b). A significant reduction in broiler chick caecal Salmonella counts was observed following feed treatment from hatch with $1 \%$ formic or propionic acid and an oral challenge of $10^{6} \mathrm{cfu}$ $S$. Typhimurium at two days of age (McHan and Shotts, 1992). Preparations of acids that are stabilised to foregut absorption (and thus may be directly active in the hindgut) can be more effective, as discussed below.

Experiments using artificial contamination of feed allow the continuous exposure of chicks or older birds to known levels of Salmonella. A mix of formic and propionic acids, added after Salmonella contamination, protected most young chicks from colonisation by $S$. Kedougou in feed contaminated via a desiccated coconut carrier, but only when inclusion levels were at $\geq 0.5 \%$ and contamination did not exceed $500 \mathrm{cfu} / \mathrm{g}$ (Hinton and Linton, 1988). The effect of the chemicals on the incidence of Salmonella-positive feed samples was much less marked. A similar contamination protocol was used in a series of experiments reported by Allen (1997), using $S$. Kedougou and $S$. Typhimurium. One percent inclusion of a formic/propionic acid product provided complete protection against colonisation of young chicks by $50 \mathrm{cfu} / \mathrm{g}$ $S$. Kedougou, but this concentration offered only modest protection against $200 \mathrm{cfu} / \mathrm{g}$ $S$. Kedougou or $15 \mathrm{cfu} / \mathrm{g} S$. Typhimurium, demonstrating a serovar difference. Reducing the concentration of the product to $0.68 \%$ or $0.3 \%$ provided only partial protection for chicks from 50 or $5 \mathrm{cfu} / \mathrm{g}$ respectively of $S$. Kedougou. Adding $1 \%$ to heavily-contaminated $\left(10^{3} \mathrm{cfu} / \mathrm{g} S\right.$. Kedougou) fishmeal did not protect chicks eating starter ration into which it was incorporated. Formic acid at 0.5 to $1.5 \%$ in feed was associated with reduced counts of $S$. Gallinarum (introduced continually in the feed) throughout the alimentary tract of young broilers (Al-Natour and Alshawabkeh, 2005).

Exposure of experimental animals to naturally-contaminated feed generally involves a challenge dose that is unknown, probably variable, and possibly intermittent. When naturallycontaminated feed was treated with formic acid and fed a week later to broiler chicks from one day of age, protection from colonisation was prevented if the acid inclusion level was more than $0.4 \%$ (Hinton et al., 1985). Hinton and Linton (1988) found that formic acid at $0.6 \%$ (but not $0.3 \%$ ) inclusion completely protected chicks from natural feed contamination by Salmonella from one day to seven weeks of age. Protection was dependent on use of the acid from day one. In a field study where Salmonella was endemic in broiler breeders (Humphrey and Lanning, 1988), the introduction of formic acid at $0.5 \%$ in feed was associated with a significant reduction in the incidence of Salmonella-positive samples from the flock environment and from newly-hatched broiler chicks. Pigs exposed naturally and artificially to Salmonella in feed, and to $0.9 \%$ formic acid also in feed, showed a significant reduction in isolations of Salmonella from internal lymph nodes at slaughter, when compared with those on untreated feed (Vanderwal, 1979).

Organic acid treatment of feed can reduce the colonisation of chicks via non-feed routes, i.e. following environmental exposure to Salmonella via seeder birds or by naturally or artificially-contaminated litter and surfaces. A formic/propionic acid product at $0.68 \%$ inclusion proved protective of chicks exposed to the lower end of a range of surface contamination, but not to higher levels, nor to litter contaminated with $10^{3}-10^{5} \mathrm{cfu} / \mathrm{g}$ (Allen, 1997). Calcium formate at $0.72 \%$ in feed did not protect chicks from colonisation via an unquantified challenge from feed and previously used litter, neither did feed treatment at $0.36 \%$ protect from colonisation via seeder birds inoculated with $10^{7}-10^{8} \mathrm{cfu} S$. Typhimurium (Izat et al., 1990a). 
A novel approach to the administration of organic acids in feed has been the use of shortchain fatty acids stabilised on microbeads to provide activity in the chicken large intestine (van Immerseel et al., 2004b, 2005). Hatchlings were relatively protected from colonisation by orally-administered $S$. Enteritidis by stabilised butyric acid at just $0.16 \%$ in feed, whereas similarly-presented formic acid and acetic acid actually increased colonisation compared with controls, possibly due to local effects on the large intestinal epithelium. When free and stabilised sodium butyrate, singly and in a 1:1 combination at low inclusion rates of around $0.063 \%$ were fed from hatching, it was the combination of free plus stabilised acid treatment that proved most protective for chicks against an oral bolus of $10^{6} \mathrm{cfu} S$. Enteritidis given at five days of age. The microencapsulated preparation was also protective, but free sodium butyrate at a similar inclusion rate was not. Stabilised sodium butyrate at around $0.08 \%$ inclusion in feed reduced the excretion of $S$. Enteritidis by broilers during exposure via seeder birds throughout the rearing period, but there was no difference between treatment and control groups in the rates of caecal colonisation by six weeks of age.

Acid treatment of drinking water. The use of organic acids in drinking water rather than feed has the advantage of allowing animals to be treated during periods of feed withdrawal (particularly pre-slaughter) when susceptibility to infection with Salmonella and other pathogens is likely to be increased (Ramirez et al., 1997; Byrd et al., 1998; Corrier et al., 1999), whilst potentially retaining some or all of the acids' in vivo activity against ingested Salmonella. In addition, it may destroy or reduce any vegetative pathogens in the water itself. Acids in water may also be used, strategically or throughout rearing, to suppress endemic Salmonella infections in pigs or poultry. A drawback in many drinking water systems is corrosion affecting galvanised pipes, joints and nipple drinkers.

In an in vitro examination of organic acid preparations, tested over a range of concentrations, Allen (1997) found that a formic/propionic acid product reduced Salmonella in water to undetectable levels within $4 \mathrm{~h}$ when added at concentrations of $0.15 \%$ or above. However, the product when given at this level in water failed to influence the colonisation of chicks challenged artificially via the feed with moderate numbers (around $50 \mathrm{cfu} / \mathrm{g}$ feed) of the pathogen. Al-Chalaby et al. (1985) reported that an existing natural Salmonella carrier state did not prove susceptible to treatment with a commercial aqueous acid treatment, despite Salmonella being eliminated from the water in the drinkers.

Byrd et al. (2001) dosed broiler chickens twice orally with $10^{8}$ cfu of $S$. Typhimurium and then added $0.5 \%$ acetic, formic or lactic acid to the drinking water during an eight-hour period without feed. Both formic and lactic acids produced a significant reduction in the proportion of positive crops and on the numbers of Salmonella present. However, in common with treated feed studies involving concentrated oral boluses of Salmonella, there was no effect on prevalence or levels of caecal carriage. In a further experiment involving naturally-infected commercial broilers, $0.44 \%$ lactic acid in drinking water significantly $(P \leq 0.001)$ reduced the proportion of Salmonella-contaminated crops post-slaughter, as well as the prevalence of positive carcass-rinse samples. One publication (Parker et al., 2006), by a company marketing organic acid blends for use in drinking water, reported that an undefined acid blend at $0.04-$ $0.08 \%$ in water during the first two weeks and the final week of broiler rearing did not prevent intestinal colonisation in the face of oral challenge of hatchlings by $10^{7} \mathrm{cfu} S$. Heidelberg. However, the treatment did reduce the incidence and degree of colonisation of in-contact birds and of environmental contamination by Salmonella after seven weeks, indicating some 
activity against a lower-level horizontal challenge. Using another proprietary blend (Parker et al., 2007), differences in caecal colonisation of in-contact birds were observed within 2 weeks, although consistent differences in crop isolations were not seen between treatment and control groups.

The study of Parker et al. (2006) reported that water acidification $(\leq 0.08 \%$ acid blend) led to a significant improvement in feed conversion, but had no effect on bird weight-gain or mortality. A formic/propionic acid product at $\geq 0.2 \%$ did reduce weight gain in chicks (Allen, 1997). Chaveerach et al. (2004) reported that treatment of drinking water with (unspecified) organic acids had no effect on broiler weight-gain and caused no visible histological changes in gut epithelium.

Letellier et al. (2000) added $0.02 \%$ formic acid to the drinking water of early-weaned piglets and challenged them with $S$. Typhimurium two weeks later. Reductions in Salmonella colonisation of mesenteric lymph nodes were not observed with this treatment. Of three Salmonella-positive finishing pig herds treated with a buffered acid mix at around $0.2 \%$ in drinking water ( $\mathrm{pH} 3.5-3.9)$, one showed a marked reduction in Salmonella serological titres in comparison with untreated control groups, and the others showed a statistical trend towards reduced serological responses (van der Wolf et al., 2001). In another study, a product comprising organic acids plus ammonium formate was used $(0.2 \%$ in drinking water) in 10 pig herds with high Salmonella titres, indicating high endemic Salmonella challenge (van der Heijden $e t$ al.). This treatment was followed by a reduction in titres, which paralleled that in 10 herds treated with feed acidification. This reduction in titres was not observed in five hightitre herds using improved hygienic practices alone. Salmonella was not eliminated from the herds over a two-year acid treatment period. Over a shorter period, an unspecified acid preparation administered to finishing pigs for the last two weeks prior to slaughter reduced drinking water $\mathrm{pH}$ to 3.6-4.0, but had no effect on Salmonella shedding (De Busser et al., 2009).

In reviewing the use of organic acids in feed or water given to weaned and fattening pigs, Giannenas (2006) noted that, aside from anti-Salmonella effects, improvements in growth-rate and feed efficiency could be anticipated, but in practice the results were highly variable. Improvements in daily weight gain associated with a blend of organic acids in water appeared to be specific to later growth phases, and was associated with reduced feed efficiency (Walsh et al., 2007). The same author observed that combined acid-treatment of feed and drinking water had negative effects on growth performance via reduced feed intake.

\section{Formaldehyde}

Formaldehyde has a high level of disinfectant activity against most bacteria, effected by irreversible cross-linking of proteins, and has been shown to be the most effective compound to use for disinfection of poultry houses which have been contaminated by Salmonella (Davies and Wray, 1995). It is less likely to be inactivated by organic matter than most disinfectant classes, but requires several hours to achieve its full effect. Despite the absence of conclusive evidence of toxicity in humans who regularly work with formaldehyde, this substance has come to be regarded as hazardous (Arts et al., 2006). However, it does not appear to cause adverse effects or tissue residues in animals given feed or rations which have been treated (Duncan and Adams, 1972; Vanderwal, 1979; Buckley and Fisher, 1984; Bugarski et al., 1990; McAllister et al., 1992; Allen, 1993). In the EU, it is permitted as a feed 
processing aid, pending a review of the use of biocides and preservatives in foods and feedingstocks.

The long-term protective effect of formaldehyde may be limited to some extent by evaporation after mixing, unless feed is held in closed bins (David et al., 1972; Khan et al., 2003). For this reason some commercial formaldehyde-based products also contain acids, such as propionic acid, and other antimicrobial compounds such as bacterial membranedisrupting terpenes (Trombetta et al., 2005; Carrique-Mas et al., 2007). This produces a synergistic combination allowing lower levels of formaldehyde and acids to be used which minimises fuming, operator hazard and corrosiveness. The antibacterial effects of formaldehyde are not considered to rely to any significant extent on processes occurring after ingestion by the animal. Given the mode of microbicidal action, and in contrast to organic acids, the apparent efficacy of formaldehyde is not likely to be substantially enhanced by low $\mathrm{pH}$ or an intestinal environment. However, other variables known to affect acid susceptibility, such as strain variation, moisture, matrix structure and composition, and natural versus artificial contamination, are likely to result in variations in observed efficacy between and within studies.

Formalin (37\% w/v formaldehyde) at $\geq 0.12 \%$ reduced counts of Salmonella in moistened meat and bone meal, by contrast to bacterial growth observed in the presence of various organic and inorganic acids at up to $0.3 \%$ (Smyser and Snoeyenbos, 1979). The bactericidal effect was gradual at $0.12 \%$ and rapid at $0.2 \%$. It was also reported that at very low moisture (2\%), $1 \%$ formalin had little effect on Salmonella in meat and bone meal. Formaldehyde, applied as fumigant gas to chick feed (five minutes' exposure with mixing), reduced artificial Salmonella contamination to low levels immediately after treatment and to undetectable levels $12 \mathrm{~h}$ later (Duncan and Adams, 1972). Relatively concentrated formaldehyde (formalin 0.5 $1 \% \mathrm{v} / \mathrm{w}$ ) was rapidly effective in rendering inoculated $S$. Typhimurium undetectable in feed (Moustafa et al., 2002).

Allen (1997) reported that $1 \%$ of a combined formaldehyde/propionic acid/terpene product (giving an inclusion rate of around $0.3 \% \mathrm{w} / \mathrm{w}$ formaldehyde) was an effective treatment for fishmeal artificially contaminated with $10^{3} \mathrm{cfu} / \mathrm{g}$ Salmonella, such that a starter ration prepared from it did not infect chicks. At inclusion levels of $0.25-0.70 \%$, formaldehyde was associated with 1 to $\geq 2 \log _{10}$ unit reductions in natural Salmonella contamination of oilseed meals within $48 \mathrm{~h}$ (Hansen et al., 1995). When a formaldehyde/propionic acid product was added at $1-2 \%$ to artificially-contaminated animal protein meals, contamination of $10^{2}-10^{4} \mathrm{cfu} / \mathrm{g}$ was eliminated within 24h (Carrique-Mas et al., 2007). Unmasking treatment of pre-enrichment broths using histidine suggested that masking had occurred in up to half of samples with a high $\left(10^{3}\right.$ or $\left.10^{4} \mathrm{cfu} / \mathrm{g}\right)$ initial Salmonella count, but not at lower contamination levels. Results were not different $72 \mathrm{~h}$ after application. A field study using a formaldehyde/ propionic acid/ terpene product at $0.27 \% \mathrm{w} / \mathrm{w}$ in layer feed found productivity benefits but no change in environmental microbial populations (Anderson et al., 2002).

\section{Other chemical treatments}

Essential oils are plant-derived mixtures of terpenes, terpenoids and low molecular-weight organic compounds of several classes, which exert antimicrobial effects probably by a range of mechanisms that includes the disruption of bacterial membranes (Trombetta et al., 2005; Benchaar et al., 2008). Essential oils, or constituents such as terpenes, are sometimes used in 
combination with other agents (organic acids $+/$ - formaldehyde) to improve the microbicidal effect of these agents, particularly at near-neutral $\mathrm{pH}$ before feed consumption.

Chlorate salts have recently been investigated for their ability to effect suppression in vivo of enteric facultative anaerobes, including Salmonella and E. coli, via a bacterial respiratory nitrate reductase, expressed in anaerobic conditions, which converts chlorate to cytotoxic chlorite. Susceptible bacteria expressing the enzyme, which can be induced by exposure to nitrate and some organic nitro compounds, are selectively killed (Anderson et al., 2005). Experiments have concentrated on the use of chlorate preparations for the suppression of Salmonella and E. coli in the intestinal flora in the period leading up to slaughter, as the effects are rapid. Significant reductions in crop and caecal colonisation (reduced incidence and $1-3 \log _{10}$ unit lower counts) by orally-inoculated Salmonella Typhimurium and Enteritidis serovars have been reported after using chlorate preparations in feed or water for broilers and turkeys (Byrd et al., 2003, 2008; Burnham et al., 2004; Anderson et al., 2005; McReynolds et al., 2005). Among pigs, similar significant reductions in large intestinal counts of both inoculated Salmonella and E. coli of the natural flora have been reported from weaners and finishers treated with chlorate preparations (Anderson et al., 2004, 2005, 2006). Pre-treatment with oral nitrate or certain nitro compounds appears to potentiate the effect of chlorate (Burnham et al., 2004; Anderson et al., 2005, 2006). Ruminants also show reductions in large intestinal E. coli, of the order of $1-3 \log _{10}$ units within $24-48 \mathrm{~h}$ of chlorate administration, but the additional benefits of nitrogen compound pre-treatment are uncertain, possibly because of their metabolism in the rumen (Anderson et al., 2005; Gutierrez-Bañuelos et al., 2007). Chlorate is currently an experimental additive, as it does not have authorisation for use in food-producing animals.

\section{Summary, based upon the cited publications plus unpublished industry data}

High concentrations of organic acids can be used as a processing aid in the treatment of contaminated ingredients, with the aim of reducing or eliminating Salmonella contamination before consumption of the feedstuff. Additional benefits of using acids in this mode include the suppression of Salmonella contamination in feedmill, farm storage and feeding equipment through which the material passes, and some residual antimicrobial effect in the finished feed, depending on the inclusion rate of the treated ingredient. Formaldehyde, used alone or in concert with other agents, can be used in the same mode. The treatment of compounded feed, or of grain fed as straights, with high concentrations of organic acids (generally $\geq 2 \%$ ) runs into problems of palatability, corrosion and cost.

Single acids, acid blends and buffered blends including acid salts can be used at lower concentrations (generally up to 1\%) in finished feeds, relying to some extent on actions in vivo for their full antimicrobial effect. One approach to increasing the effect of organic acids before ingestion has been to incorporate compounds which disrupt bacterial cell membranes, which appears to have the effect of reducing the bacterial barrier to the entry of organic acids at around neutral $\mathrm{pH}$. The observed effects of buffered mixes in dry feeds may be equivalent to or poorer than a similar concentration of a straight acid, notwithstanding potential handling benefits of buffered products. With recommended inclusion rates and artificial Salmonella contamination, reported reductions from $<1$ up to $2 \log _{10}$ units, over $24 \mathrm{~h}$ to several days are typical of such blends. Evidence as to the time-frame of organic acid anti-Salmonella effects in feed before ingestion is conflicting: in some studies little additional reduction in bacterial counts was seen beyond $24 \mathrm{~h}$ post-application, whereas in others, incremental effects were 
seen over $48 \mathrm{~h}$ to several days. The inclusion rate may be significant, whereby high concentrations achieve most of the bacterial kill within $24 \mathrm{~h}$.

Whereas several studies have examined the protection against Salmonella colonisation afforded to individuals by organic acids, others have focussed on the effects of organic acids in feed or water upon groups of poultry or pigs where Salmonella is already endemic. In these situations, organic acids in straight acid or salt formulations appear to have a progressive, subtotal suppressive effect on environmental contamination and excretion of Salmonella, and are associated with reduced humoral immune responses of animals to the pathogen.

Formaldehyde appears to act rapidly ex vivo at all but marginal application rates, and a $24 \mathrm{~h}$ measurement point is often used. In artificially-contaminated feed, $10^{3}-10^{4} \mathrm{cfu} / \mathrm{g}$ Salmonella was not detectable $24 \mathrm{~h}$ after treatment with formaldehyde in a blended product, and commercial studies suggest that concentrations of either $0.1 \% \mathrm{w} / \mathrm{w}$ alone, or of $0.06 \% \mathrm{w} / \mathrm{w}$ with $0.02 \%$ propionic acid plus terpenes and surfactant, have been associated with $2-5 \log _{10}$ unit reductions of naturally-occurring Salmonella in animal protein and compound feeds. Some feed matrices (particularly certain oilseed meals) and/or Salmonella strains can appear relatively resistant, showing lesser reductions in some studies.

Some commercial studies indicate that liquid formulations can be more efficacious or more potent than powdered preparations of the same chemical mix, suggesting that dispersal and penetration of chemicals are significant factors affecting antibacterial action. The form (powdered versus liquid) and stage of application (ingredients, blending before milling, mixing after milling, surface application to pellets) will clearly influence the effects of chemical treatment. Masking of viable Salmonella has been demonstrated with organic acids and formaldehyde, and this may lead to overestimation of the antimicrobial efficacy of these agents in unconsumed feed. However, masked organisms may have been rendered more susceptible to lethal injury after ingestion, so the implications of masking in terms of risk of infection to the animal remain unclear.

The persistence of protection by organic acids may extend for several weeks and is potentially useful, although it has to be regarded as limited by both time and the level of challenge. Formaldehyde is generally considered to have a rapid but not prolonged antimicrobial effect once applied, and formaldehyde-containing products with a claim for persistent effects also contain other antimicrobial agents. In one commercial study, the effect of a blended acid treatment on Enterobacteriaceae counts in feed reduced with transfer from mill to farm. There are many factors, including recontamination challenge and moisture levels, which may contribute to this diminution of effect.

The antibacterial effects of organic acids are markedly enhanced in a moist or wet low-pH $(<5)$ environment, such as the crop, monogastric stomach or the abomasum of pre-ruminant cattle and sheep. There may additionally be sublethal injury inflicted under these conditions that renders Salmonella more susceptible to other body defences. Typical inclusion rates of organic acids for compounded feeds do not appear consistently to depress the foregut $\mathrm{pH}$ in chickens, but this is in any event low enough to create conditions for potent organic acid antibacterial actions, and this may be the primary mechanism for the protective effect of organic acids in feed against Salmonella. By contrast, the $\mathrm{pH}$ of rumen contents is normally above 5.5, and it infrequently drops below 5.0 in healthy animals (Briggs et al., 1957; Kleen et al., 2003; Grove-White, 2004). In addition, endogenous volatile fatty acids are efficiently absorbed across the rumen wall, so it seems likely that exogenous ingested organic acids 
would not exert a useful antimicrobial activity in the $\mathrm{pH}$ conditions of the rumen of ruminating cattle or sheep, nor would they reach the abomasum in significant quantities in such animals.

Modest inclusion rates of organic acids in feed (typically $<1 \% \mathrm{w} / \mathrm{w}$ ) appear protective against typical natural Salmonella contamination of feed when used before exposure. However, the level of contamination at which this protection is overcome varies widely, and there is evidence that serovar, feed matrix and mode of contamination (artificial versus natural) will all influence this. Oilseed meals and animal protein concentrates in particular may contain Salmonella cells protected by lipids or protein, or in dense microfoci.

It appears to be easy to overcome feed- or water-administered organic acids by oral dosing of chicks with Salmonella at doses of $10^{4}$ cfu or above, which is consistent with protection generated in the foregut. Once this is overcome by a bolus dose, colonisation of the hindgut can proceed. Accordingly, when the organic acid dose is increased to a level that depresses crop $\mathrm{pH}$ or the organic acid is delivered in a stabilised form that is active in the hindgut, oral boluses of Salmonella are less successful at establishing colonisation of chicks. There is also evidence that caecal Salmonella concentrations in young chicks may be suppressed by nonstabilised organic acids in feed, although a mechanism for this is unclear. There are no published animal challenge studies with a quantified initial contamination rate and defined formaldehyde treatment of feed.

Organic acids and chlorate have both been proposed as potentially of value in short-term treatments aimed at reducing Salmonella excretion and transmission at times of stress, such as pre-slaughter, and delivered via feed or water.

\section{Conclusions}

The decontamination of feed ingredients and of compound feedstuffs using chemical agents needs to take account of likely initial contamination rates, opportunities for recontamination in storage and transfer, and the susceptibility of the target livestock to Salmonella infection. In addition, the mode of action of the agents will alter the judgement of when to use an agent and how best to assess efficacy. Organic acids, their salts, formaldehyde and membrane-disrupting compounds, singly or in combination may provide adequate protection against new Salmonella challenges in feed, and can act progressively to reduce endemic Salmonella problems, provided the challenge level is not too great. Treatments at recommended application rates may fail if application is uneven, if particularly resistant Salmonella strains are present, or if existing environmental contamination exceeds the protection threshold. 'Problem' batches of ingredients, particularly protein concentrates, are best identified in advance and treated intensively before incorporation into compound feed. The success of chemical treatment may not necessarily be measured in the prevention or elimination of a Salmonella problem, but in a progressive diminution of endemic infections in a herd or flock.

Some agents can usefully be assessed for efficacy by studies in dry feed, and assessments of ingredient decontamination following high chemical application rates may be reliable, with careful methodology. However, the results of many examinations can show substantial variation in results owing to factors both known (e.g. masking, strain variation, natural vs. artificial contamination, effects of background flora) and unknown. The most complete assessment of efficacy for any chemical treatment would involve controlled challenge studies plus field studies, involving realistic feed handling and the appropriate type and age of 
livestock. Few of these have been performed. There is also a need for the development of one or more reference methods for evaluating the efficacy of such products, so that informed decisions can be made on selection of suitable products for a particular mode of application from the large number of such preparations available.

Finally, as with any treatment, chemical treatments must be applied consistently. Errors in application caused by mechanical failure, blocked nozzles, electrostatic or sedimentation effects or miscalculation of dose rates can lead to contaminated material entering the feed supply. If chemical treatment is used with material that is known to be contaminated, its effectiveness should ideally be checked before the batch is used. Over-reliance on a single method will predispose pathogen control to periodic failure, so chemical treatments are best used as one element in a package of feed safety measures such as careful testing and selection of ingredients, mill hygiene and control of recontamination.

\section{Acknowledgements}

Much of this review was funded by the UK Department for Environment, Food and Rural Affairs (Defra) under projects OZ0328 and OZ0329 of the Foodborne Zoonoses research programme. The assistance of several companies (Anitox, Novus, Nutreco-Selko, Optivite and Perstorp) in providing unpublished efficacy data is gratefully acknowledged. 


\section{References}

Adams CA. A review of chemical treatment of raw materials and finished products in reducing pathogens. Feed Compounder 1991; 11:30-33.

Al-Chalaby ZAM, Hinton $\mathrm{MH}$ and Linton AH. Failure of drinking water sanitization to reduce the incidence of natural Salmonella in broiler chickens. Vet. Rec. 1985; 116:364365.

Al-Natour MQ and Alshawabkeh KM. Using varying levels of formic acid to limit growth of Salmonella gallinarum in contaminated broiler feed. Asian-australas. J. Anim. Sci. 2005; 18:390-395.

Al-Tarazi YH and Alshawabkeh K. Effect of dietary formic and propionic acids on Salmonella Pullorum shedding and mortality in layer chicks after experimental infection. J. Vet. Med. B Infect. Dis. Vet. Public Health 2003; 50:112-117.

Allen PC. Effects of formaldehyde fumigation of housing on carotenoid pigmentation in 3 breeds of chickens. Poult. Sci. 1993; 72:1040-1045.

Allen VM. Salmonella infections in broiler chickens: epidemiology and control during incubation and brooding. Ph.D Thesis. Department of Veterinary Medicine, University of Bristol, UK. 1997.

Álvarez-Ordóñez A, Fernandez A, Lopez M, Arenas R and Bernardo A. Modifications in membrane fatty acid composition of Salmonella typhimurium in response to growth conditions and their effect on heat resistance. Int. J. Food Microbiol. 2008; 123:212-219.

Álvarez-Ordóñez A, Fernández A, Bernardo A and López M. Comparison of acids on the induction of an acid tolerance response in Salmonella typhimurium, consequences for food safety. Meat Sci. 2009; 81:65-70.

Anderson KE, Sheldon BW and Richardson K. Effect of Termin- $8^{\circledR}$ compound on the productivity of brown egg laying chickens and environmental microbial populations. $91^{\text {st }}$ Annual Meeting of the Poultry Science Association. Newark, Delaware, 11-14 August, 2002.

Anderson RC, Hume ME, Genovese KJ, Callaway TR, Jung YS, Edrington TS, Poole TL, Harvey RB, Bischoff KM and Nisbet DJ. Effect of drinking-water administration of experimental chlorate ion preparations on Salmonella enterica serovar Typhimurium colonization in weaned and finished pigs. Vet. Res. Commun. 2004; 28:179-189.

Anderson RC, Harvey RB, Byrd JA, Callaway TR, Genovese KJ, Edrington TS, Jung YS, McReynolds JL and Nisbet DJ. Novel preharvest strategies involving the use of experimental chlorate preparations and nitro-based compounds to prevent colonization of food-producing animals by foodborne pathogens. Poult. Sci. 2005; 84:649-654.

Anderson RC, Jung YS, Genovese KJ, McReynolds JL, Callaway TR, Edrington TS, Harvey $\mathrm{RB}$ and Nisbet DJ. Low level nitrate or nitroethane preconditioning enhances the bactericidal effect of suboptimal experimental chlorate treatment against Escherichia coli 
and Salmonella typhimurium but not Campylobacter in swine. Foodborne Pathog. Dis. 2006; 3:461-465.

Arts JHE, Rennen MAJ and de Heer C. Inhaled formaldehyde: evaluation of sensory irritation in relation to carcinogenicity. Regul. Toxicol. Pharmacol. 2006; 44:144-160.

Baik HS, Bearson S, Dunbar S and Foster JW. The acid tolerance response of Salmonella typhimurium provides protection against organic acids. Microbiol. (SGM) 1996; 142 31953200 .

Bains BS and MacKenzie MA. Transmission of Salmonella through an integrated poultry organisation. Poult. Sci. 1974; 53:1114-1118.

Bauer J and Hormansdorfer S. Salmonellosis in farm animals. Fleischwirtschaft 1996; 76:726-728.

Benchaar C, Calsamiglia S, Chaves AV, Fraser GR, Colombatto D, McAllister TA and Beauchemin KA. A review of plant-derived essential oils in ruminant nutrition and production. Anim. Feed Sci. Technol. 2008; 145:209-228.

Berk PA, Jonge R, Zwietering MH, Abee T and Kieboom J. Acid resistance variability among isolates of Salmonella enterica serovar Typhimurium DT104. J. Appl. Microbiol. 2005; 99:859-866.

Beuchat LR and Ryu JH. Produce handling and processing practices. Emerg. Infect. Dis. 1997; 3:459-465.

Boyer CIJ, Narotsky S, Bruner DW and Brown JA. Salmonellosis in turkeys and chickens associated with contaminated feed. Avian Dis. 1962; 6:43-50.

Briggs PK, Hogan JP and Reid RL. Effect of volatile fatty acids, lactic acid and ammonia on rumen pH in sheep Aust. J. Agric. Res. 1957; 8:674 - 690.

Bryan FL, Ayres JC and Kraft AA. Contributory sources of salmonellae on turkey products. Am. J. Epidemiol. 1968; 87:578-591.

Buchanan RL and Edelson SG. pH-dependent stationary-phase acid resistance response of enterohemorrhagic Escherichia coli in the presence of various acidulants. J. Food Prot. 1999; 62:211-218.

Bucher O, Holley RA, Ahmed R, Tabor H, Nadon C, Ng LK and D'Aoust JY. Occurrence and characterization of Salmonella from chicken nuggets, strips, and pelleted broiler feed. J. Food Prot. 2007; 70:2251-2258.

Buckley KE and Fisher LJ. Formaldehyde residues in tissues and milk of dairy cattle consuming formalin-treated liquid whey. Research Review, Research Station, Agassiz B.C. 1984; March-August:14-15.

Bugarski D, Handzic R, Sivcevic A and Stanic I. Effect of feeding regimen and formaldehyde-treated soyabean meal on the productivity of dairy cows. Veterinaria (Sarajevo) 1990; 39:21-30. 
Burnham MR, Byrd JA, McReynolds JL, Anderson RC, Genovese KJ, Kubena LF and Nisbet J. Pre-nitrate adaptation prior to experimental chlorate product feed or water supplementation effectively reduces Salmonella. Poult. Sci. 2004; 83:1772.

Byrd JA, Corrier DE, Hume ME, Bailey RH, Stanker LH and Hargis BM. Effect of feed withdrawal on Campylobacter in the crops of market-age broiler chickens. Avian Dis. 1998; 42:802-806.

Byrd JA, Hargis BM, Caldwell DJ, Bailey RH, Herron KL, McReynolds JL, Brewer RL, Anderson RC, Bischoff KM, Callaway TR and Kubena LF. Effect of lactic acid administration in the drinking water during preslaughter feed withdrawal on Salmonella and Campylobacter contamination of broilers. Poult. Sci. 2001; 80:278-283.

Byrd JA, Anderson RC, Callaway TR, Moore RW, Knape KD, Kubena LF, Ziprin RL and Nisbet DJ. Effect of experimental chlorate product administration in the drinking water on Salmonella Typhimurium contamination of broilers. Poult. Sci. 2003; 82:1403-1406.

Byrd JA, Burnham MR, McReynolds JL, Anderson RC, Genovese KJ, Callaway TR, Kubena LF and Nisbet DJ. Evaluation of an experimental chlorate product as a preslaughter feed supplement to reduce Salmonella in meat-producing birds. Poult. Sci. 2008; 87:1883-1888.

Carrique-Mas JJ, Bedford S and Davies RH. Organic acid and formaldehyde treatment of animal feeds to control Salmonella: efficacy and masking during culture. J. Appl. Microbiol. 2007; 103:88-96.

Chaveerach P, Keuzenkamp DA, Lipman LJA and Van Knapen F. Effect of organic acids in drinking water for young broilers on Campylobacter infection, volatile fatty acid production, gut microflora and histological cell changes. Poult. Sci. 2004; 83:330-334.

Cherrington CA, Hinton $\mathrm{M}$ and Chopra I. Effect of short-chain organic acids on macromolecular synthesis in Escherichia coli. J. Appl. Microbiol. 1990; 68:69-74.

Cherrington CA, Chopra I and Hinton M. Acid treatment of feed for the control of salmonella infections in poultry. Vet. Annu. 1991; 31:90-95.

Church DC. Rumen fermentation of natural feedstuffs. In: Digestive Physiology and Nutrition of Ruminants, Vol 1 (2nd ed.). Portland, Oregon: Oxford Press, 1979, pp. 280-281.

Corrier DE, Byrd JA, Hargis BM, Hume ME, Bailey RH and Stanker LH. Presence of Salmonella in the crop and ceca of broiler chickens before and after preslaughter feed withdrawal. Poult. Sci. 1999; 78:45-49.

Corry JEL, Allen VM, Hudson WR, Breslin MF and Davies RH. Sources of salmonella on broiler carcasses during transportation and processing: modes of contamination and methods of control. J. Appl. Microbiol. 2002; 92:424-432.

Cox NA, Bailey JS, Thomson JE and Juven BJ. Salmonella and other Enterobacteriaceae found in commercial poultry feed. Poult. Sci. 1983; 62:2169-2175.

Crump JA, Griffin PA and Angulo FJ. Bacterial contamination of animal feed and its relationship to human foodborne illness. Clin. Infect. Dis. 2002; 35:859-865. 
Dargatz DA, Strohmeyer RA, Morley PS, Hyatt DR and Salman MD. Characterization of Escherichia coli and Salmonella enterica from cattle feed ingredients. Foodborne Pathog. Dis. 2005; 2:341-347.

David WAL, Taylor G and Ellaby S. Fumigant action of formaldehyde incorporated in a semi-synthetic diet on Granulosis Virus of Pieris brassicae and its evaporation from diet. J. Invertebr. Pathol. 1972; 19:76-82.

Davies R, Breslin M, Corry JE, Hudson W and Allen VM. Observations on the distribution and control of Salmonella species in two integrated broiler companies. Vet. Rec. 2001; 149:227-232.

Davies RH and Wray C. Observations on disinfection regimens used on Salmonella Enteritidis-infected poultry units. Poult. Sci. 1995; 74:638-647.

Davis MA, Hancock DD, Rice DH, Call DR, DiGiacomo R, Samadpour M and Besser TE. Feedstuffs as a vehicle of cattle exposure to Escherichia coli O157:H7 and Salmonella enterica. Vet. Microbiol. 2003; 95:199-210.

de Albuquerque R, Ito NMK and Miyaji CI. Treatment of feeds of chickens with organic acids: study of bactericidal efficacy and evaluation of recovery techniques for Salmonella spp. Braz. J. Vet. Res. Anim. Sci. 1998; 35:279-282.

De Busser EV, Dewulf J, Nollet N, Houf K, Schwarzer K, De Sadeleer L, De Zutter L and Maes D. Effect of organic acids in drinking water during the last 2 weeks prior to slaughter on Salmonella shedding by slaughter pigs and contamination of carcasses. Zoonoses Public Health 2009; 56:129-136.

de Jonge R, Ritmeester WS and van Leusden FM. Adaptive responses of Salmonella enterica serovar Typhimurium DT104 and other S. Typhimurium strains and Escherichia coli $\mathrm{O} 157$ to low pH environments. J. Appl. Microbiol. 2003; 94:625-632.

Dennis I and Blanchard P. Effect of feeding potassium diformate on incidence of Salmonella infection on a commercial unit. The Pig Journal 2004; 54:157-160.

Diebold $\mathrm{G}$ and Eidelsburger U. Acidification of diets as an alternative to antibiotic growth promoters. In: Antimicrobial growth promoters - where do we go from here? Barug D, de Jong J, Kies AK and Verstegen MWA (Eds.) Wageningen, Netherlands: Wageningen Academic Publishers, 2006, pp. 311-327.

Duncan MS and Adams AW. Effects of a chemical additive and of formaldehyde gas fumigation on Salmonella in poultry feeds. Poult. Sci. 1972; 51:797-802.

El-Sharoud WM and Niven GW. The influence of ribosome modulation factor on the survival of stationary-phase Escherichia coli during acid stress. Microbiol. (SGM) 2007; 153:247253.

Enternet surveillance hub. Enter-net annual report 2004; surveillance of enteric pathogens in Europe and beyond. London: HPA Centre for Infections, Colindale, 2006. 
European Food Safety Authority. The Community summary report on trends and sources of zoonoses, zoonotic agents, antimicrobial resistance and foodborne outbreaks in the European Union in 2005. The EFSA Journal 2006a; 94:65-73.

European Food Safety Authority. Opinion of the Scientific Panel on Biological Hazards on "Risk assessment and mitigation options of Salmonella in pig production". EFSA Journal 2006b; 341:1-131.

European Food Safety Authority. The Community summary report on trends and sources of zoonoses and zoonotic agents in the European Union in 2007. The EFSA Journal 2009; 223: 14-94.

Fratamico PM. Tolerance to stress and ability of acid-adapted and non-acid-adapted Salmonella enterica serovar Typhimurium DT104 to invade and survive in mammalian cells in vitro. J. Food Prot. 2003; 66:1115-1125.

Gabis DA. Environmental factors affecting enteropathogens in feed and feed mills. In: Colonization control of human bacterial enteropathogens in poultry. Blankenship LC (Ed.) San Diego: Academic Press, 1991, pp. 23-28.

Giannenas IA. Organic acids in pig and poultry nutrition. Journal of the Hellenic Veterinary Medical Society 2006; 57:51-62.

Glickman LT, McDonough PL, Shin SJ, Fairbrother JM, LaDue RL and King SE. Bovine salmonellosis attributed to Salmonella anatum-contaminated haylage and dietary stress. J. Am. Vet. Med. Assoc. 1981; 178:1268-1272.

Gorden J and Small PL. Acid resistance in enteric bacteria. Infect. Immun. 1993; 61:364-367.

Greenacre EJ, Lucchini S, Hinton JCD and Brocklehurst TF. The lactic acid-induced acid tolerance response in Salmonella enterica serovar Typhimurium induces sensitivity to hydrogen peroxide. Appl. Environ. Microbiol. 2006; 72:5623-5625.

Grove-White D. Rumen healthcare in the dairy cow. In Pract. 2004; 26:88-95.

Gutierrez-Bañuelos H, Anderson RC, Carstens GE, Slay LJ, Ramlachan N, Horrocks SM, Callaway TR, Edrington TS and Nisbet DJ. Zoonotic bacterial populations, gut fermentation characteristics and methane production in feedlot steers during oral nitroethane treatment and after the feeding of an experimental chlorate product. Anaerobe 2007; 13:21-31.

Ha SD, Maciorowski KG, Kwon YM, Jones FT and Ricke SC. Survivability of indigenous microflora and a Salmonella typhimurium marker strain in poultry mash treated with buffered propionic acid. Anim. Feed Sci. Technol. 1998; 75:145-155.

Hacking WC, Mitchell WR and Carlson HC. Salmonella investigation in an Ontario feed mill. Can. J. Comp. Med. 1978; 42:400-406.

Hall G. Microbial control of poultry feeds. International Hatchery Practice 1988; 3:7-11.

Hansen ID, Israelsen $M$ and Jakobsen EE. The efficiency of chemical agents in eliminating naturally occurring Salmonella in feeds. Kraftfutter 1995; 10:428-436. 
Heres L, Engel B, Urlings HAP, Wagenaar JA and van Knapen F. Effect of acidified feed on susceptibility of broiler chickens to intestinal infection by Campylobacter and Salmonella. Vet. Microbiol. 2004; 99:259-267.

Hinton M, Linton AH and Perry FG. Control of salmonella by acid disinfection of chicks' food. Vet. Rec. 1985; 116:502.

Hinton M. Salmonella infection in chicks following the consumption of artificially contaminated feed. Epidemiol. Infect. 1988; 100:247-256.

Hinton $\mathrm{M}$ and Linton $\mathrm{AH}$. Control of salmonella infections in broiler chickens by the acid treatment of their feed. Vet. Rec. 1988; 123:416-421.

Hinton M, Mead GC and Impey CS. Protection of chicks against environmental challenge with Salmonella enteritidis by 'competitive exclusion' and acid-treated feed. Lett. Appl. Microbiol. 1991; 12:69-71.

Högberg A and Lindberg JE. Influence of cereal non-starch polysaccharides and enzyme supplementation on digestion site and gut environment in weaned piglets. Anim. Feed Sci. Technol. 2004; 116:113-128.

Hume ME, Corrier DE, Ambrus S, Hinton A, Jr. and DeLoach JR. Effectiveness of dietary propionic acid in controlling Salmonella typhimurium colonization in broiler chicks. Avian Dis. 1993; 37:1051-1056.

Humphrey TJ and Lanning DG. The vertical transmission of salmonellas and formic acid treatment of chicken feed. A possible strategy for control. Epidemiol. Infect. 1988; 100:4349.

Izat AL, Adams MH, Cabel MC, Colberg M, Reiber MA, Skinner JT and Waldroup PW. Effects of formic acid or calcium formate in feed on performance and microbiological characteristics of broilers. Poult. Sci. 1990a; 69:1876-1882.

Izat AL, Tidwell NM, Thomas RA, Reiber MA, Adams MH, Colberg M and Waldroup PW. Effects of a buffered propionic acid in diets on the performance of broiler chickens and on microflora of the intestine and carcass. Poult. Sci. 1990b; 69:818-826.

Jones FT, Axtell RC, Rives DV, Scheideler SE, Tarver FR, Walker RL and Wineland MJ. A survey of Salmonella contamination in modern broiler production. J. Food Prot. 1991; 54:502-507.

Jones FT and Richardson KE. Salmonella in commercially manufactured feeds. Poult. Sci. 2004; 83:384-391.

Jones PW, Collins P, Brown GT and Aitken M. Transmission of Salmonella mbandaka to cattle from contaminated feed. J. Hyg. (Lond). 1982; 88:255-263.

Karatzas KAG, Hocking PM, Jørgensen F, Mattick K, Leach S and Humphrey TJ. Effects of repeated cycles of acid challenge and growth on the phenotype and virulence of Salmonella enterica. J. Appl. Microbiol. 2008; 105:1640-1648. 
Khan M and Katamay M. Antagonistic effect of fatty acids against Salmonella in meat and bone meal. Appl. Microbiol. 1969; 17:402-404.

Khan MZ, Ali Z, Muhammad G, Khan A and Mahmood F. Pathological effects of formalin (37\% formaldehyde) mixed in feed or administered into the crops of white leghorn cockerels. J. Vet. Med. A Physiol. Pathol. Clin. Med. 2003; 50:354-358.

Kidd RS, Rossignol AM and Gamroth MJ. Salmonella and other Enterobacteriaceae in dairy cow feed ingredients: antimicrobial resistance in Western Oregon. J. Environ. Health 2002; 64:9-16.

Kleen JL, Hooijer GA, Rehage J and Noordhuizen J. Subacute ruminal acidosis (SARA): a review. J. Vet. Med. A Physiol. Pathol. Clin. Med. 2003; 50:406-414.

Knox WA, Galbraith NS, Lewis MJ, Hickie GC and Johnston HH. A milk-borne outbreak of food poisoning due to Salmonella heidelberg. J. Hyg. (Lond). 1963; 61:175-185.

Kwon YM and Ricke SC. Induction of acid resistance of Salmonella typhimurium by exposure to short-chain fatty acids. Appl. Environ. Microbiol. 1998; 64:3458-3463.

Letellier A, Messier S, Lessard L and Quessy S. Assessment of various treatments to reduce carriage of Salmonella in swine. Can. J. Vet. Res. 2000; 64:27-31.

Lewis SM and Dehority BA. Microbiology and ration digestibility in the hindgut of the ovine. Appl. Environ. Microbiol. 1985; 50:356-363.

MacKenzie MA and Bains BS. Dissemination of Salmonella serotypes from raw feed ingredients to chicken carcases. Poult. Sci. 1976; 55:957-960.

Martin $\mathrm{H}$ and Maris P. An assessment of the bactericidal and fungicidal efficacy of seventeen mineral and organic acids on bacterial and fungal food industry contaminants. Sci. Aliments 2005; 25:105-127.

McAllister TA, Beauchemin KA, McClelland LA and Cheng KJ. Effect of formaldehydetreated barley or escape protein on nutrient digestibility, growth and carcass traits of feedlot lambs. Can. J. Anim. Sci. 1992; 72:309-316.

McHan F and Shotts EB. Effect of feeding selected short-chain fatty acids on the in vivo attachment of Salmonella typhimurium in chick ceca. Avian Dis. 1992; 36:139-142.

McReynolds J, Kubena L, Byrd J, Anderson R, Ricke S and Nisbet D. Evaluation of Salmonella enteritidis in molting hens following administration of all experimental chlorate product (9 days) in the drinking water. Poult. Sci. 2005; 84:S108-109.

Mead PS, Slutsker L, Dietz V, McCaig LF, Bresee JS, Shapiro C, Griffin PM and Tauxe RV. Food-related illness and death in the United States. Emerg. Infect. Dis. 1999; 5:607-625.

Morita T, Murayama Y and Iida T. Salmonella contamination in materials for oil meal and the oil-meal manufacturing plant. Jpn. J. Food Microbiol. 2003; 20:117-122.

Moustafa GZ, Zaki MM and Badawy EM. Hygienic control of Salmonella in artificially contaminated feed. Veterinary Medical Journal (Giza) 2002; 50:239-246. 
Nayak R, Kenney PB, Keswani J and Ritz C. Isolation and characterisation of Salmonella in a turkey production facility. Br. Poult. Sci. 2003; 44:192-202.

Nesse LL, Nordby K, Heir E, Bergsjoe B, Vardund T, Nygaard H and Holstad G. Molecular analyses of Salmonella enterica isolates from fish feed factories and fish feed ingredients. Appl. Environ. Microbiol. 2003; 69:1075-1081.

Newell KW, McClarin R, Murdock CR, MacDonald WN and Hutchinson HL. Salmonellosis in Northern Ireland, with special reference to pigs and salmonella contaminated pig meal. J. Hyg. (Lond). 1959; 57:92-105.

Österberg J, Vågsholm I, Boqvist S and Sternberg Lewerin S. Feed-borne outbreak of Salmonella Cubana in Swedish pig farms: risk factors and factors affecting the restriction period in infected farms. Acta Vet. Scand. 2006; 47:13-22.

Papenbrock S, Stemme K, Amtsberg G, Verspohl J and Kamphues J. Investigations on prophylactic effects of coarse feed structure and/or potassium diformate on the microflora in the digestive tract of weaned piglets experimentally infected with Salmonella Derby. J. Anim. Physiol. Anim. Nutr. (Berl.) 2005; 89:84-87.

Park SY, Birkhold SG, Kubena LF, Nisbet DJ and Ricke SC. Survival of a Salmonella typhimurium poultry marker strain added as a dry inoculum to zinc and sodium organic acid amended feeds. J. Food Safety 2003; 23:263-274.

Parker D, Hofacre C, Mathis GF, Quiroz MA, Knight C and Dibner J. Organic acid water treatment reduced Salmonella horizontal transmission in broiler chickens. Proceedings of the 12th European Poultry Conference. Verona, Italy, September 12-14. World's Poultry Science Association, $2006 . \quad$ Available at http://www.animalscience.com/uploads/additionalfiles/wpsaverona.htm (online).

Parker D, Hofacre C, Mathis GF, Quiroz MA, Knight C and Dibner J. Organic acid water treatment effective in decreasing Salmonella colonization and horizontal transmission in broiler chickens. Proceedings of the 16th European Symposium on Poultry Nutrition. Strasbourg, France, August 26-30. World's Poultry Science Association, 2007.

Pennington JH, Brooksbank NH, Poole PM and Seymour F. Salmonella virchow in a chickenpacking station and associated rearing units. Br. Med. J. 1968; 4:804-806.

Pinchasov Y and Jensen LS. Effect of short-chain fatty acids on voluntary feed of broiler chicks. Poult. Sci. 1989; 68:1612-1618.

Primm ND. Field experiences with the control of Salmonella introduction into turkey flocks via contaminated feeds. Proceedings of the $47^{\text {th }}$ Annual Western Poultry Disease Conference. Sacramento, California. 1998, pp. 27-30.

Pumfrey L and Nelson CE. Use of a most probable number method modified with a deoxyribonucleic acid probe to monitor control by food preservatives of natural Salmonella contamination in animal meat meals. Poult. Sci. 1991; 70:780-784.

Ramirez GA, Sarlin LL, Caldwell DJ, Yezak CR, Hume ME, Corrier DE, Deloach JR and Hargis BM. Effect of feed withdrawal on the incidence of Salmonella in the crops and ceca of market age broiler chickens. Poult. Sci. 1997; 76:654-656. 
Ricke SC. Perspectives on the use of organic acids and short chain fatty acids as antimicrobials. Poult. Sci. 2003; 82:632-639.

Ricke SC. Ensuring the safety of poultry feed. In: Food safety control in the poultry industry. Mead GC (Ed.) Cambridge, UK: Woodhead Publishing Ltd, 2005, pp. 174-194.

Russell JB. Another explanation for the toxicity of fermentation acids at low $\mathrm{pH}$ : Anion accumulation versus uncoupling. J. Appl. Bacteriol. 1992; 73:363-370.

Schleifer JH, Juven BJ, Beard CW and Cox NA. The susceptibility of chicks to Salmonella montevideo in artificially contaminated poultry feed. Avian Dis. 1984; 28:497-503.

Semple AB, Turner GC and Lowry DM. Outbreak of food-poisoning caused by Salmonella virchow in spit-roasted chicken. Br. Med. J. 1968; 4:801-803.

Shapcott RC. Practical aspects of Salmonella control: progress report on a programme in a large broiler integration. In: Proceedings of the International Symposium on Salmonella, New Orleans, 19-20 July 1984. Snoeyenbos GH (Ed.) Kennet Square, Pennsylvania, USA: American Association of Avian Pathologists, 1985, pp. 109-114.

Skrivanova E, Marounek M, Benda V and Brezina P. Susceptibility of Escherichia coli, Salmonella sp. and Clostridium perfringens to organic acids and monolaurin. Vet. Med. (Praha). 2006; 51:81-88.

Smyser CF and Snoeyenbos GH. Evaluation of organic acids and other compounds as Salmonella antagonists in meat and bone meal. Poult. Sci. 1979; 58:50-54.

Taylor J and McCoy JN. Salmonella and arizona infections. In: Foodborne infections and intoxications. Riemann H (Ed.) New York: Academic Press, 1969, pp. 3-72.

Theron MM and Lues JFR. Organic acids and meat preservation: a review. Food Rev. Internat. 2007; 23:141-158.

Thompson JL and Hinton M. Antibacterial activity of formic and propionic acids in the diet of hens on salmonellas in the crop. Br. Poult. Sci. 1997; 38:59-65.

Trombetta D, Castelli F, Sarpietro MG, Venuti V, Cristani M, Daniele C, Saija A, Mazzanti G and Bisignano G. Mechanisms of antibacterial action of three monoterpenes. Antimicrob. Agents Chemother. 2005; 49:2474-2478.

van der Heijden M, van Dam H, Niewerth D and Frankena K. Effectiveness of Salmonella control strategies in fattening pigs. Proceedings of the SafePork 2005, 6th International Symposium on the Epidemiology and Control of Foodborne Pathogens in Pork. Rohnert Park, California, September 6-9. National Pork Board, USA, 2005, pp. 145-148.

van der Wolf PJ, van Schie FW, Elbers ARW, Engel B, van der Heijden HMJF, Hunneman WA and Tielen MJM. Administration of acidified drinking water to finishing pigs in order to prevent Salmonella infections. Vet. Q. 2001; 23:121-125.

van Immerseel F, Cauwerts K, Devriese LA, Haesebrouck F and Ducatelle R. Feed additives to control Salmonella in poultry. Worlds Poult. Sci. J. 2002; 58:501-513. 
van Immerseel F, de Buck J, Pasmans F, Velge P, Bottreau E, Fievez V, Haesebrouck F and Ducatelle R. Invasion of Salmonella enteritidis in avian intestinal epithelial cells in vitro is influenced by short-chain fatty acids. Int. J. Food Microbiol. 2003; 85:237-248.

van Immerseel F, de Buck J, Boyen F, Bohez L, Pasmans F, Volf J, Sevcik M, Rychlik I, Haesebrouck F and Ducatelle R. Medium-chain fatty acids decrease colonization and invasion through hilA suppression shortly after infection of chickens with Salmonella enterica serovar Enteritidis. Appl. Environ. Microbiol. 2004a; 70:3582-3587.

van Immerseel F, Fievez V, Buck Jd, Pasmans F, Martel A, Haesebrouck F and Ducatelle R. Microencapsulated short-chain fatty acids in feed modify colonization and invasion early after infection with Salmonella Enteritidis in young chickens. Poult. Sci. 2004b; 83:69-74.

van Immerseel F, Boyen F, Gantois I, Timbermont L, Bohez L, Pasmans F, Haesebrouck F and Ducatelle R. Supplementation of coated butyric acid in the feed reduces colonization and shedding of Salmonella in poultry. Poult. Sci. 2005; 84:1851-1856.

van Immerseel F, Russell JB, Flythe MD, Gantois I, Timbermont L, Pasmans F, Haesebrouck F and Ducatelle R. The use of organic acids to combat Salmonella in poultry: a mechanistic explanation of the efficacy. Avian Pathol. 2006; 35:182-188.

Vanderwal P. Salmonella control of feedstuffs by pelleting or acid treatment. Worlds Poult. Sci. J. 1979; 35:70-78.

Veldman A, Vahl HA, Borggreve GJ and Fuller DC. A survey of the incidence of Salmonella species and Enterobacteriaceae in poultry feeds and feed components. Vet. Rec. 1995; 136:169-172.

Veterinary Laboratories Agency. Salmonella in livestock production in GB: 2005 report. Veterinary Laboratories Agency UK. 2006. Available at http://www.defra.gov.uk/vla/reports/rep_salm_rep05.htm (online).

Waldroup A, Kaniawati $\mathrm{S}$ and Mauromoustakos A. Performance characteristics and microbiological aspects of broilers fed diets supplemented with organic acids. J. Food Prot. 1995; 58:482-489.

Walsh MC, Sholly DM, Hinson RB, Saddoris KL, Sutton AL, Radcliffe JS, Odgaard R, Murphy $\mathbf{J}$ and Richert BT. Effects of water and diet acidification with and without antibiotics on weanling pig growth and microbial shedding. J. Anim. Sci. 2007; 85:17991808.

Waterman SR and Small PLC. Acid-sensitive enteric pathogens are protected from killing under extremely acidic conditions of $\mathrm{pH} 2.5$ when they are inoculated onto certain solid food sources. Appl. Environ. Microbiol. 1998; 64:3882-3886.

Wheeler JG, Sethi D, Cowden JM, Wall PG, Rodrigues LC, Tompkins DS, Hudson MJ and Roderick PJ. Study of infectious intestinal disease in England: rates in the community, presenting to general practice, and reported to national surveillance. Br. Med. J. 1999; 318: $1046-1050$. 